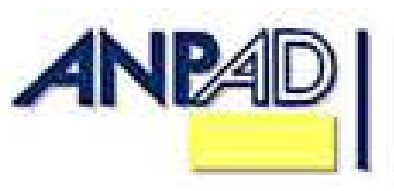

Disponível em

http://www.anpad.org.br/rac

RAC, Rio de Janeiro, v. 16, n. 3,

pp. 459-478, Maio/Jun. 2012

(c) EY-NG $^{-\mathrm{N}}$

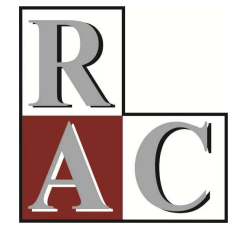

Documentos e Debates:

\title{
Pesquisa Científica da Área de Marketing no Brasil: uma Revisão da Primeira Década do Século 21
}

\section{Scientific Research on Marketing in Brazil: a Review of the First Decade of the 21th Century}

\author{
Cláudio Hoffmann Sampaio * \\ E-mail: csampaio@pucrs.br \\ Pontifícia Universidade Católica do Rio Grande do Sul - PUCRS \\ Porto Alegre, RS, Brasil. \\ Marcelo Gattermann Perin \\ E-mail: mperin@pucrs.br \\ Pontifícia Universidade Católica do Rio Grande do Sul - PUCRS \\ Porto Alegre, RS, Brasil. \\ Fernando Bins Luce \\ E-mail: fbluce@ea.ufrgs.br \\ Escola de Administração - Universidade Federal do Rio Grande do Sul - PPGA/UFRGS \\ Porto Alegre, RS, Brasil. \\ Mirela Jeffman dos Santos \\ E-mail: mirelajs@gmail.com \\ Pontifícia Universidade Católica do Rio Grande do Sul - PUCRS \\ Porto Alegre, RS, Brasil. \\ Fernando de Oliveira Santini \\ E-mail: fernando.santini@fsg.br \\ Pontifícia Universidade Católica do Rio Grande do Sul - PUCRS \\ Porto Alegre, RS, Brasil. \\ Marta Olivia Rovedder de Oliveira \\ E-mail: marta.oliveira@unipampa.edu.br \\ Universidade Federal do Rio Grande do Sul - UFRGS, Universidade Federal do Pampa - UNIPAMPA \\ Porto Alegre, RS, Brasil. \\ Geanderson de Souza Lenz \\ E-mail: geanderson.lenz@restinga.ifrs.edu.br \\ Instituto Federal de Educação, Ciência e Tecnologia do Rio Grande do Sul - IFRS \\ Porto Alegre, RS, Brasil. \\ Pontifícia Universidade Católica do Rio Grande do Sul, Av. Ipiranga, 6681, Partenon, Porto Alegre/RS, 90619-900.
}

* Endereço: Cláudio Hoffmann Sampaio

Copyright (C) 2012 RAC. Todos os direitos, até mesmo de tradução, são reservados. É permitido citar parte de artigos sem autorização prévia, desde que seja identificada a fonte. 


\section{Introdução}

A partir do ano 2000, em especial, após a publicação de dois documentos de estudos na Revista de Administração Contemporânea - RAC (Froemming et al., 2000a, 2000b) e dos artigos de Perin, Sampaio, Froemming e Luce (2000) e de F. G. D. Vieira (1998, 1999, 2000), uma série de estudos procurou trazer à tona a discussão sobre a pesquisa e produção científica da comunidade acadêmica brasileira em Administração, especificamente na área de marketing (Farias, 2004; Kovacs, Leão, Vieira, Barbosa \& Dias, 2004; Pinto \& Lara, 2008; Sampaio \& Perin, 2006) e de Administração (Caldas, Tinoco, \& Chu, 2003; Cardoso, Pereira, \& Guerreiro, 2004; Durante \& Maurer, 2007; Gonçalves, Gonçalves, \& Augusto, 2004; lizuka \& Sano, 2004; Melo \& Andreassi, 2010; Mendonça, 2011; Nascimento, Junqueira, \& Martins, 2010; Nassif, Silva, Ono, Bontempo, \& Tinoco, 2009; Tonelli, Caldas, Lacombe, \& Tinoco, 2004). Esta preocupação fomentou - além do crescimento de publicações, painéis e mesas redondas, especialmente, em encontros da ANPAD (Associação Nacional de Pós-Graduação e Pesquisa em Administração) - debates relativos à qualidade e rumos dos trabalhos realizados e publicados em âmbito nacional dentro da Ciência da Administração.

Em âmbito internacional, a discussão quanto à qualidade das pesquisas e sobre o andamento da área de marketing é tema que incorpora preocupações recentes com o futuro da disciplina (Firat et al., 2010; Reibstein, Day, \& Wind, 2009; Yadav, 2010). A edição de julho de 2011 do Journal of Marketing, comemorativa ao $75^{\circ}$ aniversário do periódico, traz uma sessão especial dedicada a refletir a respeito do futuro da disciplina e das publicações em marketing (Bolton, 2011; Kohli, 2011), em especial, quanto à relevância da pesquisa (Jaworski, 2011), do distanciamento entre a teoria e a prática (Lilien, 2011), da necessidade de maior colaboração entre a academia e as empresas (Lutz, 2011), da excessiva ênfase de rigor metodológico e de fragmentação da área (Lehmann, Mcalister, \& Staelin, 2011) e da necessidade de incremento de artigos com contribuições conceituais (Macinnis, 2011).

Tais fatos manifestam uma preocupação nacional e internacional da comunidade acadêmica em reavaliar as tendências da área de Administração e a qualidade da própria pesquisa. Dentro desse contexto, a área específica de marketing no Brasil também vem buscando uma autoanálise no que tange à sua tarefa de geração de conhecimento, dessa maneira, demonstrado um grande esforço no sentido de discutir a sua identidade e também os rumos desta disciplina, refletindo a condução de vários estudos de diagnóstico da produção científica nacional, de avaliação de posturas metodológicas alternativas e de proposição de caminhos de consolidação da disciplina no país (para um resumo dessa discussão ver Sampaio \& Perin, 2006).

Buscando integrar-se nesse esforço, este artigo tem como objetivo apresentar um levantamento e uma discussão no tocante a trabalhos de marketing publicados nos anos 2000, nos principais periódicos de administração do Brasil (Revista de Administração Contemporânea [RAC], RACEletrônica, Revista de Administração de Empresas [RAE], RAE Eletrônica, Brazilian Administration Review [BAR], Revista de Administração da Universidade de São Paulo [RAUSP], Revista de Administração da Mackenzie [RAM]), assim como nos anais dos mais importantes encontros de pósgraduação no país que possuem a divisão de marketing (Encontro da ANPAD [EnANPAD] e Encontro de Marketing da ANPAD [EMA]), e estabelecer um comparativo dos resultados com a década de 90. Para tanto, foram analisadas as estratégias e as metodologias utilizadas, visando a avaliar as suas tendências, bem como comparar a evolução ao longo dos anos.

\section{Método}

O procedimento metodológico utilizado foi o de desk research, envolvendo o conjunto de artigos científicos da área de marketing, publicados nos principais periódicos de administração do Brasil, de acordo com a classificação Qualis da CAPES, que possuem, no seu escopo, publicações em Marketing, quais sejam: RAC, RAC-Eletrônica, RAE, RAE Eletrônica, BAR, RAUSP, RAM; e nos 
anais do EMA e do EnANPAD, no período de 2000 a 2010. O processo de identificação e seleção de artigos dos anos 2000 resultou em uma relação de 1.317 artigos para a análise. Desses artigos, 187 apresentavam cunho conceitual, 91 tinham abordagem fenomenológica ou interpretativista e 1.039 eram baseados em pesquisas empíricas que apresentaram método de pesquisa envolvendo, direta ou indiretamente, alguma coleta de dados com postura positivista.

Para fins de comparação entre os períodos de 1990/1999 (década de 90) e de 2000/2010 (anos 2000), este estudo valeu-se de base de dados gerada em levantamentos anteriores, envolvendo as pesquisas científicas da década de 90 (Froemming et al., 2000a, 2000b; Perin, Sampaio, Froemming, \& Luce, 2000; Sampaio \& Perin, 2006). Dessa forma, a base total de artigos considerados no presente estudo englobou 1.569 artigos da área de marketing (252 da década de 90 e 1.317 dos anos 2000).

O processo de análise dos artigos de base empírica e de orientação positivista constituiu-se da verificação dos elementos metodológicos básicos de investigações científicas. As variáveis avaliadas para cada artigo selecionado, específicas para cada método de pesquisa (survey, qualitativa e experimental), foram adaptadas de Hoppen, Lapointe e Moreau (1997), seguindo procedimentos também adotados em Perin et al. (2000), Froemming et al. (2000a, 2000b) e Sampaio e Perin (2006). No presente artigo, contudo, são relatados apenas os resultados das variáveis comuns aos três métodos de pesquisa considerados. Foram elas: natureza da pesquisa, justificativa, teorias de base, objetivo e questão de pesquisa, hipóteses ou pressupostos de base, modelo de pesquisa, mix de métodos, operacionalização das variáveis, descrição dos procedimentos metodológicos, tipo de dados, validade externa, validade nomológica, limites do estudo, recomendações para pesquisas e recomendações aplicadas.

A avaliação destas variáveis para os anos 2000 foi realizada por um grupo de quatro pesquisadores de marketing, sendo que cada artigo foi analisado por apenas um avaliador. Contudo, buscando-se uma maior validade para o estudo, os critérios de análise foram amplamente discutidos entre os membros da equipe de avaliadores, e os casos de artigos com aspectos duvidosos foram intercambiados entre os avaliadores e analisados conjuntamente em reuniões do grupo.

Complementarmente, dois outros autores serviram de juízes, analisando novamente os artigos no intuito de verificar os níveis de coincidência. Para tanto, 90 artigos foram aleatoriamente escolhidos e avaliados (30 artigos de cada tipo de pesquisa - survey, qualitativo, experimental) pelos juízes e comparados com a avaliação inicialmente realizada pelos quatro pesquisadores. A média de concordância entre as codificações foi de $91,3 \%$ entre os juízes e os pesquisadores, e de 94,6\% entre os dois juízes. Esses valores ficaram próximos aos encontrados em outros estudos no âmbito brasileiro (Andrade \& Mazzon, 2010; Huertas \& Urdan, 2004). Os resultados da pesquisa são descritos a seguir.

\section{Resultados das Análises}

Os artigos avaliados foram inicialmente classificados por postura epistemológica - positivista e não positivista ${ }^{(1)}$ (ambos de base empírica) -, sendo também incluídos nessa análise os artigos de cunho conceitual (Figura 1a). Nessa análise, destaca-se o crescimento da produção de artigos com a aplicação de metodologias de abordagem não positivista, a partir do ano 2000, embora esse avanço se mostre tímido. Salienta-se, também, a gradativa queda do percentual de artigos conceituais publicados a partir de 1996, assim, mantendo-se em patamares abaixo de 16\%, a partir do ano 2001. Cabe registrar que, na primeira metade da década de 90, os artigos conceituais dividiam a preferência dos pesquisadores de marketing com as pesquisas positivistas de base empírica. Aparentemente, nos anos 2000, o interesse pelo desenvolvimento de artigos conceituais migrou paulatinamente para outras abordagens empíricas, positivistas e não positivistas. 


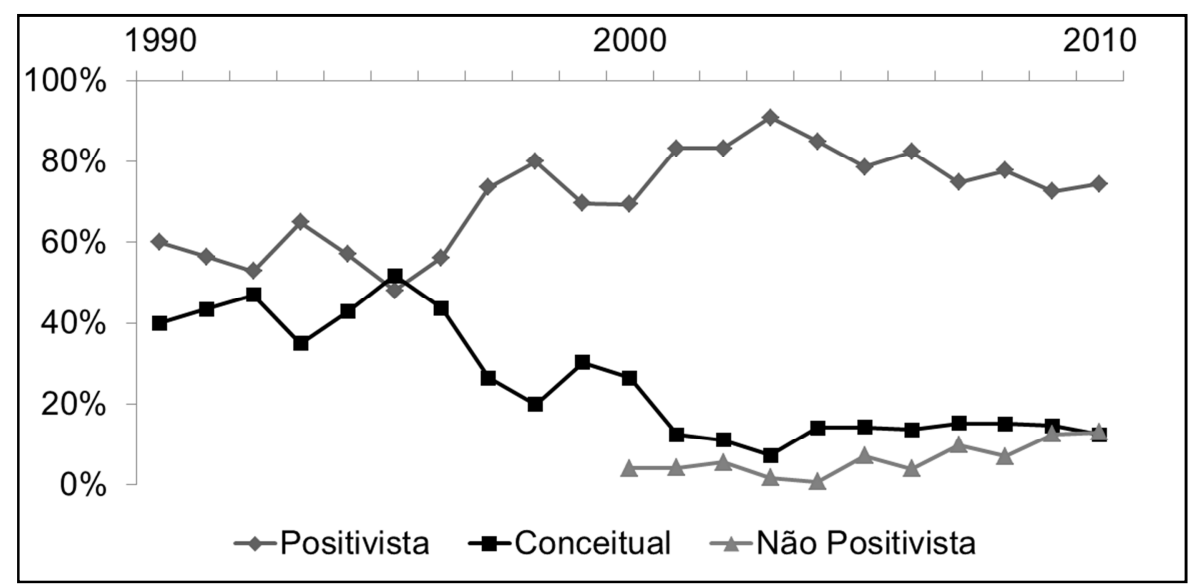

Figura 1a. Frequência de Artigos por Linha Epistemológica.

Total de 1.569 artigos (252 da década de 90 e 1.317 dos anos 2000).

Fonte: Coleta de dados.

Dentro da linha positivista, os artigos foram divididos por método de pesquisa (Figura 1b), quais sejam, survey, qualitativa ou experimental (Hoppen, Lapointe, \& Moreau, 1997; Sampaio \& Perin, 2006).

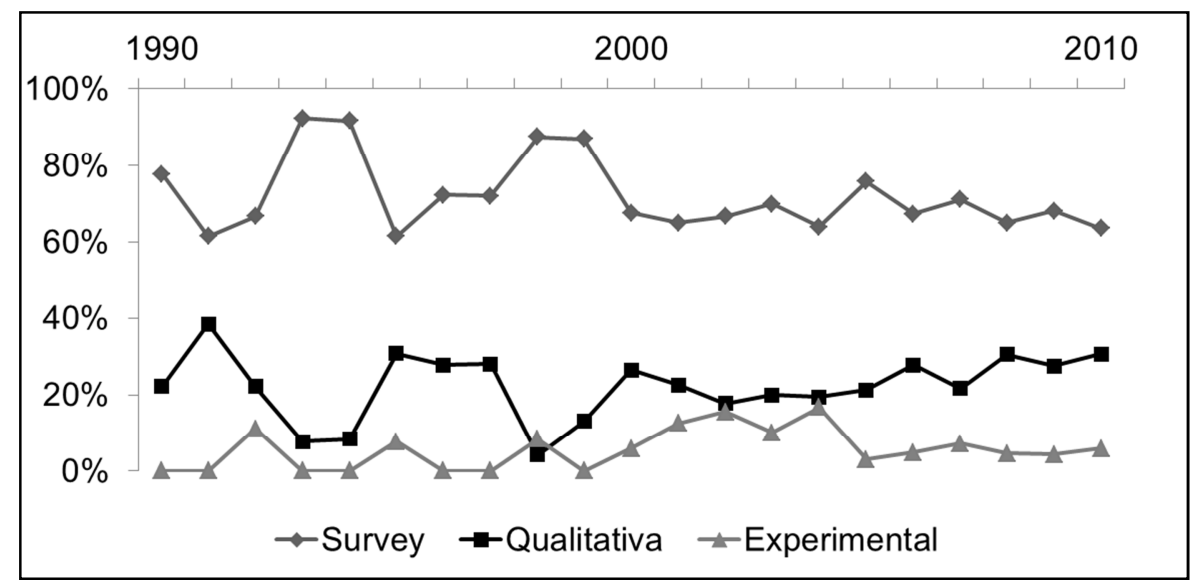

Figura 1b. Frequência de Artigos por Tipo de Pesquisa.

Total de 1.198 artigos de base empírica e abordagem positivista (159 da década de 90 e 1.039 dos anos 2000). Fonte: Coleta de dados.

Observa-se, em relação aos métodos de pesquisa adotados, a predominância das pesquisas do tipo survey ao longo dos anos, desse modo, resultando em percentuais sempre acima de $63 \%$, nos anos 2000. Nota-se, também, leve incremento no uso da metodologia experimental nas pesquisas de marketing, bem como certa estabilidade no crescimento da aplicação da abordagem qualitativa.

A seguir, são descritos os principais resultados relativos às variáveis analisadas, considerando tão somente os artigos de base empírica e postura epistemológica positivista identificados na área de marketing.

\section{Natureza da pesquisa}

A natureza da pesquisa foi classificada em exploratória, descritiva ou causal (Churchill, 1999). A Figura 2 descreve a natureza das pesquisas em marketing dos artigos analisados. 


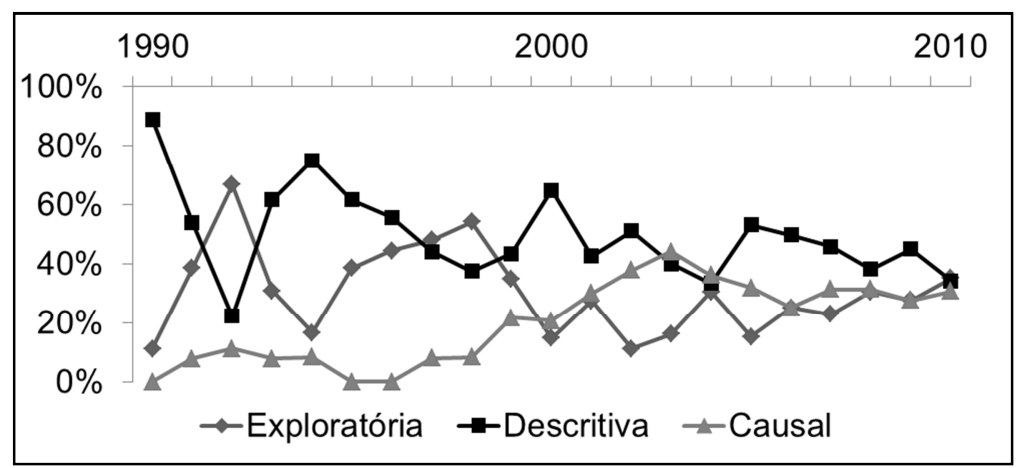

Figura 2. Frequência de Artigos por Natureza de Pesquisa.

Total de 1.198 artigos considerados.

Fonte: Coleta de dados.

Enquanto que, no início da década de 90, os estudos descritivos e exploratórios revezavam-se como os prioritários nos estudos de base empírica, a partir do ano 2000, os estudos causais passaram a disputar igualmente a preferência de utilização pelos pesquisadores de marketing. Apesar da afirmação de Sampaio e Perin (2006, p. 184) de que "os artigos de natureza descritiva seguiram o seu domínio ao longo do tempo, ampliando a sua distância para as duas outras naturezas de pesquisa", o que se observa, considerando a análise dos anos 2000, é uma aproximação de utilização das diferentes naturezas de pesquisa, resultando em percentuais bastante semelhantes no período de 2008 a 2010.

\section{Apresentação e relevância do problema de pesquisa}

Esta categoria trata de dimensões que identificam a fundamentação conceitual utilizada, bem como o registro ou não da justificativa do estudo, dos objetivos da pesquisa e suas hipóteses (Figura $3)$.

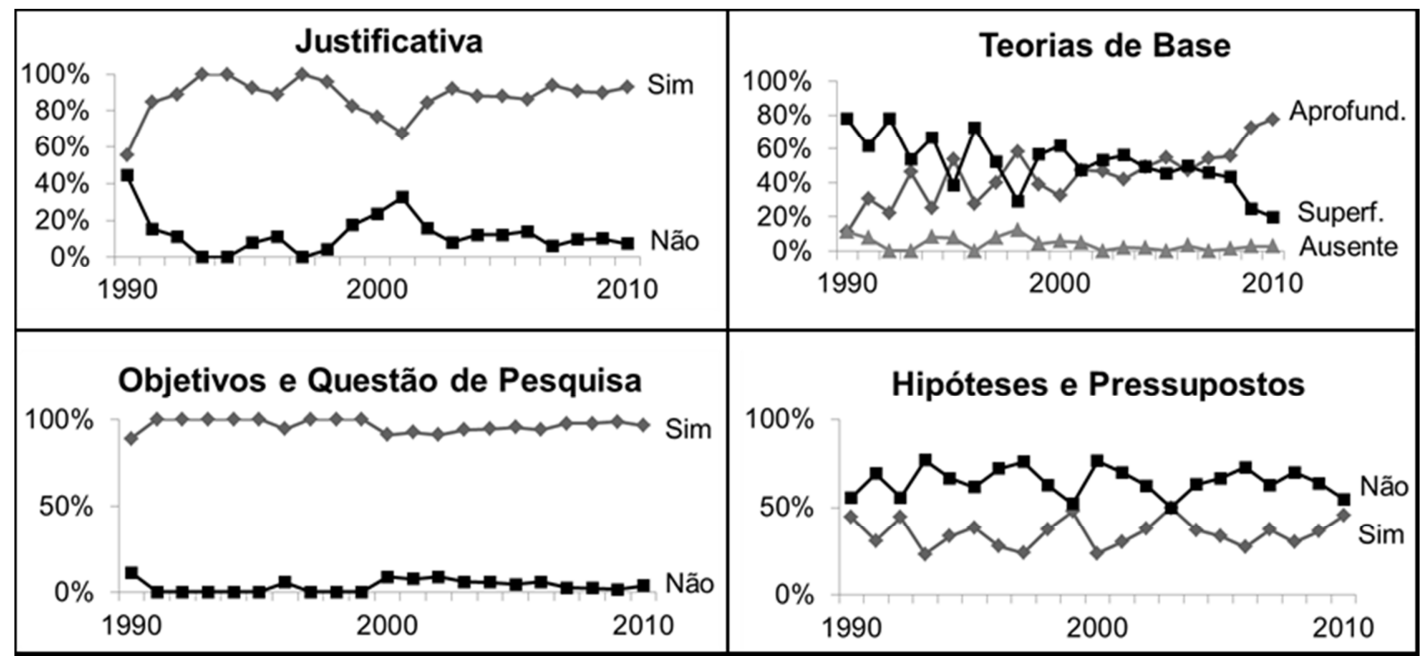

Figura 3. Frequência de Artigos por Apresentação e Relevância do Problema de Pesquisa. Total de 1.198 artigos considerados. Fonte: Coleta de dados.

Conforme a Figura 3, os artigos apresentaram, em termos gerais, uma preocupação com a apresentação e relevância do problema de pesquisa. Grande parte dos artigos expôs justificativa do estudo, bem como objetivos e questão de pesquisa. A quase totalidade dos artigos colocou a fundamentação teórica para a pesquisa descrita, entre aprofundada e superficial. Registra-se que tal comportamento já era bastante similar na década de 90 . 
No entanto, uma análise mais aprofundada a respeito do comportamento destas variáveis ao longo dos anos permite a constatação de alterações significativas em relação a duas das dimensões da apresentação e relevância do problema de pesquisa. Quanto ao uso de teorias de base, percebe-se, a partir de 2005, e com maior saliência de 2008 em diante, um aprofundamento das teorias de base e a diminuição de artigos com superficialidade de base teórica. Este fato, talvez, tenha justificativa no próprio aumento de pesquisas do tipo experimento e de natureza causal, que, por si, exigem um maior aprofundamento teórico anterior para a sua operacionalização. No tocante ao comportamento do registro no artigo de hipóteses e pressupostos de base, constata-se um comportamento cíclico, em que os períodos de 2003 a 2010 são bastante semelhantes aos de 1999 a 2003 e aos de 1995 a 1999. Também é de se registrar a constância na atenção com a especificação do objetivo e questão de pesquisa, além da dimensão de justificativa, nos dois períodos analisados.

\section{Desenho de pesquisa}

Esta categoria engloba as dimensões relacionadas com o modelo de pesquisa, utilização de mix de métodos, operacionalização das variáveis do estudo e descrição dos procedimentos metodológicos utilizados. A presença destas dimensões foi verificada em cada um dos artigos analisados. A Figura 4 resume os resultados obtidos.

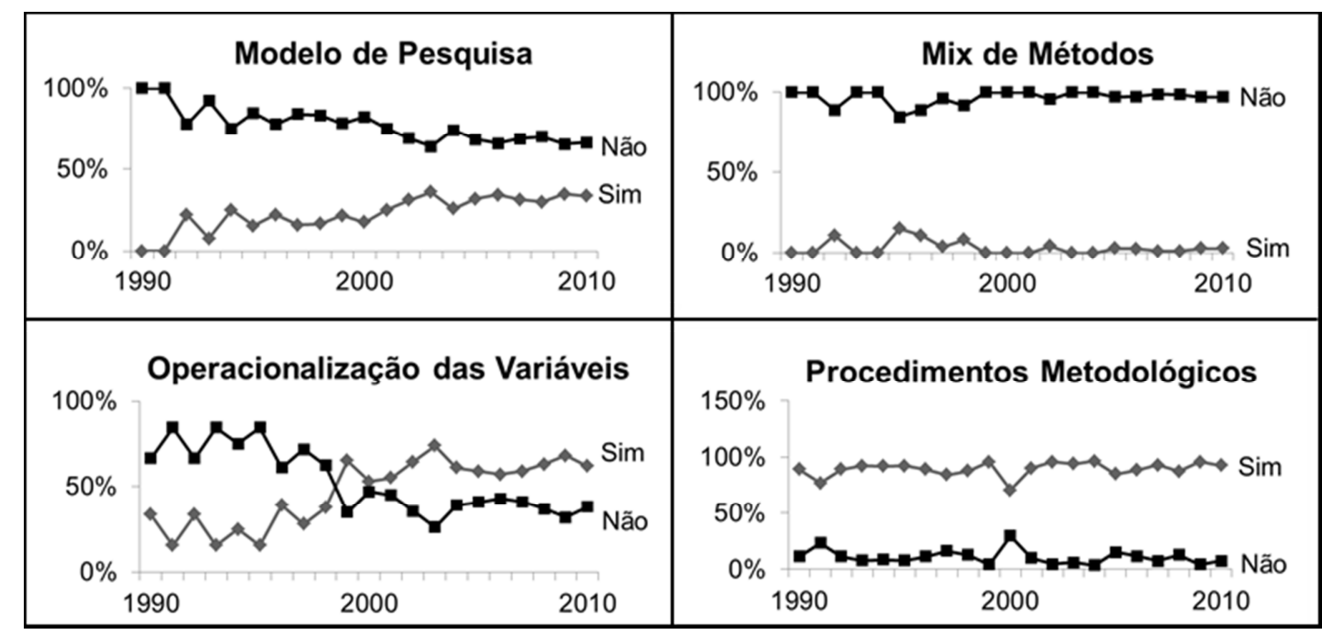

Figura 4. Frequência de Artigos por Desenho de Pesquisa.

Total de 1.198 artigos considerados.

Fonte: Coleta de dados.

A princípio, a análise dos gráficos da Figura 4 revela que, de um modo geral, nos artigos analisados, há um movimento ligeiramente crescente no refinamento do desenho de pesquisa. Contudo, ao ser examinado o comportamento evolutivo das facetas do desenho de pesquisa, fica saliente a baixa a utilização de mix de métodos de pesquisa, um comportamento estável nos dois períodos analisados. Também estável, mas com comportamento de registro positivo, parece ser a descrição dos procedimentos metodológicos ao longo dos períodos analisados.

Os resultados parecem indicar, ainda, que, nos anos 2000, há uma diminuição gradativa da diferença entre os artigos que registram modelos de pesquisa em comparação àqueles que não apresentam. Cabe ressaltar, entretanto, certa estabilidade registrada nos últimos três períodos analisados.

A variação positiva, no que se refere aos cuidados com o desenho de pesquisa, manifestou-se na presença mais marcante de operacionalização das variáveis de pesquisa. É clara a inversão das curvas de presença e ausência de operacionalização de variáveis de pesquisa, havendo um predomínio da presença deste item a partir de 1999 e durante os anos 2000, diferentemente do que ocorria na década de 90 . 


\section{Tipos de dados coletados}

Expõem-se aqui os tipos de dados coletados e/ou utilizados pelas pesquisas descritas, ou seja, dados primários (coletados especificamente para a pesquisa) ou dados secundários (já existentes em outras fontes, coletados anteriormente). A Figura 5 demonstra a distribuição de frequência dos artigos analisados por tipo de dado coletado/utilizado, considerando a possibilidade de utilização de ambos os tipos no mesmo estudo.

Percebe-se claramente que a preferência dos pesquisadores tem sido e se firmada por dados primários, não se alterando este perfil ao longo dos períodos analisados.

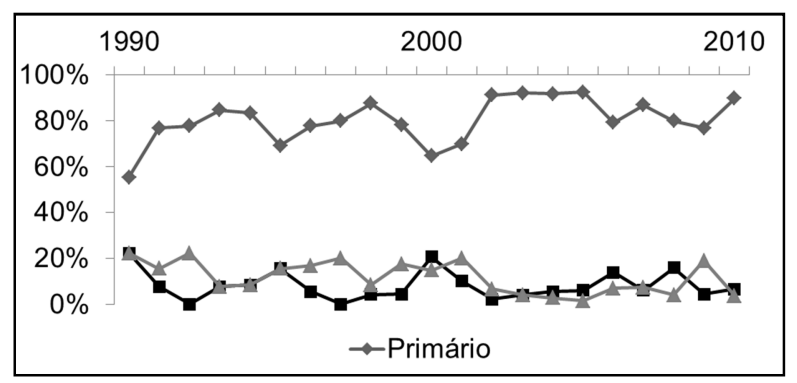

Figura 5. Frequência de Artigos por Tipo de Dado Coletado.

Total de 1.198 artigos considerados

Fonte: Coleta de dados

\section{Forma de apresentação dos resultados}

Relata-se, neste item, a forma com que os resultados de pesquisa foram apresentados nos artigos analisados, isto é, se os mesmos indicaram a validade externa ou nomológica, bem como os limites do estudo e as recomendações aplicadas para futuras pesquisas (Figura 6).

Na Figura 6, verifica-se que a preocupação dos autores com validade externa vem aumentando ao longo do tempo, dada a aproximação crescente entre a linha de ausência e a de presença de relato de validade externa nos artigos. Da mesma forma, no que se refere à apresentação, nos artigos, de discussão sobre a validade nomológica, as curvas de presença e ausência se aproximaram, invertendose em 2010. Contudo, é de ser registrar que os percentuais relativos a estes dois quesitos ainda são relativamente baixos.

Outra mudança clara se expõe na postura dos pesquisadores ao projetarem os resultados de seus estudos aos seus públicos quando das recomendações da pesquisa. É notória a inversão de foco neste quesito a partir de 2002, com a predominância de registro positivo das recomendações de pesquisa. De certa maneira, pode-se inferir que houve comportamento similar em relação às recomendações aplicadas. Depois de certa aproximação entre a linha de ausência e a de presença de relato de recomendações aplicadas entre os anos de 2001 a 2005, a partir de 2006, percebe-se uma evidente preocupação dos pesquisadores em registrar as recomendações aplicadas.

Por fim, há um sensível acréscimo, absoluto e percentual, no número de trabalhos com apresentação de limitações das pesquisas, particularmente, a partir de 2002, quando o registro de presença ultrapassou o de ausência e manteve-se estável ao longo dos anos 2000.

Numa comparação entre a década de 90 e os anos 2000, é possível enunciar que os pesquisadores de marketing depositaram maior cuidado na forma de expressar os resultados da pesquisa, seja pela aproximação entre as linhas de ausência e de presença de relato de validade externa e de validade nomológica, mas, em especial, pelas inversões para o registro positivo das linhas que 
mostram as tendências ocorridas, nos anos 2000, em relação ao registro de limites do estudo, recomendações acadêmicas e aplicadas de pesquisa.

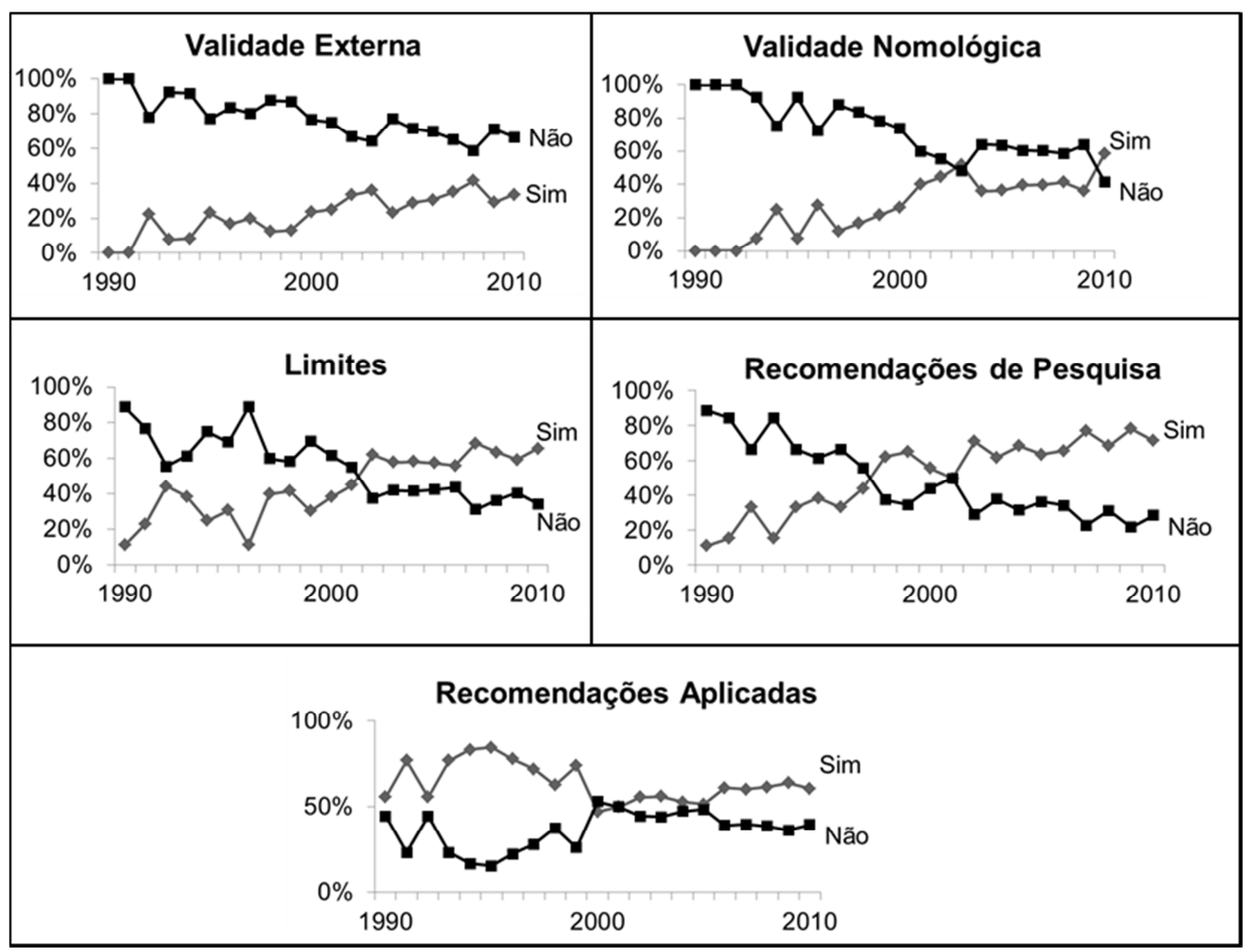

Figura 6. Frequência de Artigos por Forma de Apresentação dos Resultados.

Total de 1.198 artigos considerados.

Fonte: Coleta de dados.

\section{Síntese dos resultados e a comparação entre a década de 90 e os anos 2000}

Com o intuito de comparação, os resultados deste levantamento foram sintetizados e comparados com os da década de 90 (Froemming et al., 2000a). O espaço de tempo de produção científica analisado (de 1990 a 2010) foi dividido em dois momentos, quais sejam, a década de 90 e os anos 2000. Esta divisão deu-se por dois motivos: (a) uma intenção inicial de análise da pesquisa científica da área de marketing do Brasil nos anos 2000 e comparação entre os resultados dos dois períodos a partir dos estudos sobre a qualidade das publicações da década de 90 de Froemming et al. (2000a, 2000b); Perin et al. (2000); Sampaio e Perin (2006); e (b) a intenção de verificação de algum provável efeito sobre a produção científica do segundo momento a partir dos primeiros artigos de posicionamento crítico sobre o status quo da área de marketing do Brasil (por exemplo, Casotti, 1998, 1999; F. G. D. Vieira, 1998, 1999, 2000; Froemming et al., 2000a, 2000b; Jaime, 2000; Perin et al., 2000; Rossi \& Silveira, 1999).

Para tanto, aos dois períodos de tempo estabelecidos, foram calculados de forma agregada os seus percentuais gerais, sintetizando cada uma das variáveis consideradas no estudo e abordadas ano a ano no item anterior, considerando apenas os artigos identificados como de cunho positivista e de base empírica (Tabela 1). Nessa análise, evidenciam-se algumas modificações importantes ocorridas entre a década de 90 e os anos 2000, particularmente, em 11, das 16 dimensões analisadas.

Em relação ao tipo de pesquisa, os anos 2000 mostraram ainda um claro predomínio das pesquisas tipo survey, mesmo que já se perceba um leve decréscimo nessa liderança, como provável efeito do crescimento das abordagens qualitativas e experimentais. Já quanto à natureza da pesquisa, 
registra-se, nos anos 2000, o aumento das pesquisas causais e a diminuição dos estudos de natureza exploratória e descritiva, explicados, em parte, pelo aumento das pesquisas do tipo experimentais e das surveys causais.

No caso da apresentação e relevância do problema de pesquisa, percebe-se um comportamento bastante similar nos períodos, com predomínio dos estudos que apontam justificativa, questões de pesquisa e ausência de hipóteses. Exceção pode ser observada em relação às teorias de base, com o aumento da utilização de teorias de base mais aprofundadas nos anos 2000.

Quanto ao desenho de pesquisa, constata-se um comportamento semelhante nos dois períodos no que tange à não utilização de mix de métodos e à atenção ao apontamento da descrição dos procedimentos metodológicos. Houve um incremento nos 2000 em relação ao registro dos modelos de pesquisa, gerado, ao menos em parte, pelo acréscimo já comentado dos estudos causais. Também houve uma inversão entre os dois períodos em relação à apresentação da operacionalização das variáveis do estudo, qual seja, na década de 90, existia um predomínio de não haver o registro de operacionalização e, diferentemente, nos anos 2000, houve um predomínio em apontar a operacionalização das variáveis.

No caso do tipo de dados coletados, registra-se, nos anos 2000, o aumento da utilização de dados primários e de dados secundários; e a diminuição da utilização de ambos os dados na pesquisa de marketing.

Por fim, em atinência à forma de apresentação dos resultados, percebe-se que os pesquisadores de marketing tornaram-se mais criteriosos neste quesito durante os anos 2000, aumentando o registro em suas pesquisas quanto às validades externa e nomológica (apesar de ainda serem percentualmente baixas), limites do estudo e recomendações para pesquisas futuras em relação à década de 90 . Destacase, ainda, a diminuição do apontamento de recomendações aplicadas nos anos 2000.

Tabela 1

\section{Síntese dos Resultados}

\begin{tabular}{|c|c|c|c|c|}
\hline & & \multicolumn{2}{|c|}{ Período } & \multirow[b]{2}{*}{ sig. } \\
\hline & & 1990/99 & $2000 / 10$ & \\
\hline \multirow[t]{3}{*}{ Tipo da pesquisa } & Survey & $78,0 \%$ & $66,9 \%$ & $p<0,01$ \\
\hline & Qualitativa & $19,5 \%$ & $25,9 \%$ & \\
\hline & Experimental & $2,5 \%$ & $7,2 \%$ & \\
\hline \multirow[t]{3}{*}{ Natureza da pesquisa } & Exploratória & $40,3 \%$ & $26,2 \%$ & $p<0,01$ \\
\hline & Descritiva & $51,6 \%$ & $42,9 \%$ & \\
\hline & Causal & $8,2 \%$ & $30,9 \%$ & \\
\hline \multirow[t]{2}{*}{ Justificativa } & $\operatorname{sim}$ & $90,6 \%$ & $88,3 \%$ & $n s$ \\
\hline & não & $9,4 \%$ & $11,7 \%$ & \\
\hline \multirow[t]{3}{*}{ Teorias de base } & aprofundada & $38,4 \%$ & $55,1 \%$ & $p<0,01$ \\
\hline & superficial & $55,4 \%$ & $42,8 \%$ & \\
\hline & ausente & $6,3 \%$ & $2,1 \%$ & \\
\hline \multirow[t]{2}{*}{ Objetivo/Questão de pesquisa } & $\operatorname{sim}$ & $98,7 \%$ & $95,6 \%$ & $n s$ \\
\hline & não & $1,3 \%$ & $4,4 \%$ & \\
\hline
\end{tabular}




\section{Tabela 1 (continuação)}

\begin{tabular}{|c|c|c|c|c|}
\hline & & \multicolumn{2}{|c|}{ Período } & \multirow[b]{2}{*}{ sig. } \\
\hline & & 1990/99 & $2000 / 10$ & \\
\hline \multirow[t]{2}{*}{ Hipóteses/pressupostos de base } & $\operatorname{sim}$ & $34,6 \%$ & $34,6 \%$ & $n s$ \\
\hline & não & $65,4 \%$ & $65,5 \%$ & \\
\hline \multirow[t]{2}{*}{ Modelo de pesquisa } & $\operatorname{sim}$ & $15,7 \%$ & $31,1 \%$ & $p<0,01$ \\
\hline & não & $84,3 \%$ & $68,9 \%$ & \\
\hline \multirow[t]{2}{*}{ Mix de métodos } & $\operatorname{sim}$ & $5,0 \%$ & $1,8 \%$ & $n s$ \\
\hline & não & $95,0 \%$ & $98,2 \%$ & \\
\hline \multirow[t]{2}{*}{ Operacionalização das variáveis } & $\operatorname{sim}$ & $33,3 \%$ & $61,4 \%$ & $p<0,01$ \\
\hline & não & $66,7 \%$ & $38,6 \%$ & \\
\hline \multirow[t]{2}{*}{ Descrição dos procedimentos metodológicos } & $\operatorname{sim}$ & $88,7 \%$ & $90,2 \%$ & $n s$ \\
\hline & não & $11,3 \%$ & $9,8 \%$ & \\
\hline \multirow[t]{3}{*}{ Tipo de dados } & primários & $78,6 \%$ & $83,6 \%$ & $p<0,01$ \\
\hline & secundários & $6,3 \%$ & $9,8 \%$ & \\
\hline & ambos & $15,1 \%$ & $6,5 \%$ & \\
\hline \multirow[t]{2}{*}{ Validade externa } & $\operatorname{sim}$ & $13,2 \%$ & $32,5 \%$ & $p<0,01$ \\
\hline & não & $86,8 \%$ & $67,5 \%$ & \\
\hline \multirow[t]{2}{*}{ Validade nomológica } & $\operatorname{sim}$ & $13,8 \%$ & $42,1 \%$ & $p<0,01$ \\
\hline & não & $86,2 \%$ & $57,9 \%$ & \\
\hline \multirow[t]{2}{*}{ Limites do estudo } & $\operatorname{sim}$ & $30,8 \%$ & $59,9 \%$ & $p<0,01$ \\
\hline & não & $69,2 \%$ & $40,1 \%$ & \\
\hline \multirow[t]{2}{*}{ Recomendações para pesquisas } & $\operatorname{sim}$ & $40,3 \%$ & $68,1 \%$ & $p<0,01$ \\
\hline & não & $59,8 \%$ & $31,9 \%$ & \\
\hline \multirow[t]{2}{*}{ Recomendações aplicadas } & $\operatorname{sim}$ & $72,3 \%$ & $58,3 \%$ & $p<0,01$ \\
\hline & não & $27,7 \%$ & $41,7 \%$ & \\
\hline
\end{tabular}

Nota. Fonte: Coleta de dados.

Total de 1.198 artigos considerados.

\section{Discussão sobre os Resultados e Conclusões do Estudo}

Frente aos resultados encontrados, percebe-se uma alteração de padrões diagnosticados em estudos anteriores, por Perin et al. (2000) e por Froemming et al. (2000a, 2000b). Mais especificamente, em relação aos métodos de pesquisa aplicados pelo corpo de pesquisadores, apesar da manutenção de predomínio das pesquisas do tipo survey, é visível o crescimento da aplicação da metodologia experimental, além do despertar para a aplicação de abordagem alternativa à positivista. Já quanto à natureza da pesquisa, percebe-se um avanço da abordagem causal em detrimento do caráter exploratório da pesquisa, além da tradicional supremacia das pesquisas de âmbito descritivo. Também, como decorrência do incremento de pesquisas causais e do uso de experimentos, além do domínio das pesquisas surveys de foco descritivo, observa-se a manifestação de um aprofundamento teórico dos estudos e de uma maior utilização de modelos de pesquisa, bem como maior atenção à 
operacionalização das variáveis de estudo. Por sua vez, nota-se uma dificuldade clara na confecção de pesquisas de cunho qualitativo e aplicação de mais de um método de pesquisa.

A síntese dos resultados, bem como algumas eventuais explicações para esses resultados, pode ser agrupada nos seguintes temas, cada um deles abordado na sequência: o predomínio da abordagem positivista, as replicações da produção científica norte-americana, os programas de doutorado e as pesquisas em marketing, as lacunas no atendimento aos critérios de qualidade e o declínio de investigações conceituais, os primeiros passos na direção de abordagens metodológicas alternativas e, para finalizar, os benefícios e beneficiários da pesquisa em marketing,

\section{O predomínio da abordagem positivista}

O presente estudo, seguindo a linha dos levantamentos realizados nas principais publicações científicas no Brasil, aponta claramente para a predominância da abordagem positivista, de base empírica e de cunho quantitativo, tanto na área de Administração (ver, por exemplo, os estudos de Durante \& Maurer, 2007; Melo \& Andreassi, 2010; Mendonça, 2011; Nascimento et al., 2010; Nassif et al., 2009) quanto, mais especificamente, em Marketing (por exemplo, Farias, 2004; Kovacs et al., 2004; Pinto \& Lara, 2008; Sampaio \& Perin, 2006).

Embora Brown et al. (2005) sustentem que o conhecimento beneficiar-se-ia do uso de diversos métodos os quais compensariam as deficiências de outros, considerando que as distintas abordagens de ciência diferem em suas metodologias, parece que o movimento por novas abordagens de pesquisa, pela multidisciplinaridade e pelas perspectivas envolvendo multimétodos não se configura efetivamente na área. Apesar dos dados identificados no presente estudo mostrarem uma tímida reação de abordagens não positivistas, envolvendo, em 2010, uma parcela em torno de $10 \%$ dos artigos científicos produzidos com base empírica, evidencia-se, ainda, sobremaneira uma ênfase em artigos com abordagem empírica de cunho positivista. De acordo com Brown et al. (2005), esse domínio empiricista poderia levar a um menor estímulo intelectual, uma vez que os artigos são avaliados por pares que partilham a mesma posição metodológica, ao invés de diferentes perspectivas que estimulariam um pensamento mais provocativo.

Várias razões aparentemente entrelaçadas são apontadas pela academia como causas potenciais ao domínio positivista na área de marketing, entre elas, destacam-se o processo de revisão e aceitação das principais revistas de marketing, a formação dos pesquisadores, a pressão por publicações, a falta de treinamento adequado para outras abordagens de pesquisa, a excessiva replicação da produção científica norte-americana (para uma recente discussão de essas razões ver Lehmann et al., 2011).

Sair do paradigma positivista de base empírica dominante parece ser uma barreira importante à aceitação de publicação nas principais revistas internacionais. Nessa linha, Brown et al. (2005) declararam preocupação sobre a possibilidade de existir no processo de revisão, o que intitulou de empirical bias, isto é, o declínio dos artigos conceituais e qualitativos estaria atrelado, ao menos parcialmente, às mudanças nos processos de revisões dos principais periódicos de marketing que privilegiam uma ótica mais empiricista, metodológica e positivista (para uma discussão sobre a mudança de foco dos critérios de decisão de qualidade para a sofisticação metodológica ver Ellison, 2002). Segundo Reibstein, Day e Wind (2009), os periódicos possuem um papel central nessa questão e parecem não estar inclinados a aceitar artigos conceituais que sugiram novas direções de pesquisa. Firat et al. (2010) e Brown et al. (2005) afirmam que os editores e os revisores possuem uma grande responsabilidade em entender as várias abordagens e metodologias de uma pesquisa de qualidade, reconhecendo pesquisas baseadas em contribuição substantiva à área, ao invés de valorizarem a aderência aos paradigmas metodológicos.

É bem verdade que, no decurso dos anos, elevou-se o nível de rigor analítico dos artigos de Marketing publicados nos periódicos acadêmicos. Considerados os critérios de rigor científico da linha positivista, os resultados encontrados no presente estudo demonstram uma evolução da produção científica da área nos anos 2000 em relação à década de 90 . Não se discute, pois, a desejabilidade do rigor dentro da academia, mas há um sentimento que o rigor, acompanhado de análises complexas de 
temas não substantivos, tenha se tornado um objetivo central da disciplina de marketing (Lehmann et al., 2011). De acordo com Firat et al. (2010), existe, nos periódicos de marketing, o que eles chamam de predomínio do ritual sobre relevância, apontando que os top journals determinam um ritual metodológico que acaba se reduzindo à própria metodologia, quase que desconsiderando a importância do estudo. É a técnica dominando a relevância, chamado pelo autor de survey-dominant logic, em que os periódicos principais continuam publicando surveys com um rigoroso arsenal estatístico sobre assuntos extremamente limitados e com pouca (ou nenhuma) possibilidade de generalização e contribuição ao conhecimento da área, sendo quase uma replicação mais rebuscada daquilo que já se sabe. A técnica é por si usada mais como uma conveniência do pesquisador (os autores utilizam como exemplo as convenientes amostras de estudantes) em busca da rápida e necessária pontuação de publicação, do que para o desenvolvimento do entendimento do fenômeno de marketing.

\section{As replicações da produção científica norte-americana}

O predomínio em replicar a produção científica norte-americana, eminentemente formada dentro da corrente indutivo-estatística positivista (Pinto \& Santos, 2008), também é apontado como razão alternativa para tal dominância (Faria, 2004; Mascarenhas, Zambaldi, \& Moraes, 2011; R. Vieira, Dias, Rodrigues, \& Anjos, 2002; Rosa \& Alves, 2011). Rodrigues e Carrieri (2001) afirmam que parte dos problemas de qualidade e originalidade da produção científica nacional é decorrente da tendência dos pesquisadores de mimetizar o que é produzido especialmente nos EUA, submetendo a comunidade brasileira a operar segundo uma lógica externa, que acaba definindo quais os padrões de qualidade científica para a área de Administração (Rosa \& Alves, 2011).

Como decorrência, Firat et al. (2010) ressaltam que essa dominação tem levado a um modelo assimétrico de relações entre os idiomas, prevalecendo a língua inglesa e os valores dos EUA. Meriläinen, Tienari, Thomas e Davies (2008) e Hamel (2007) comentam sobre a dominância da língua inglesa nos periódicos científicos internacionais, sublinhando a dificuldade (ou mesmo a impossibilidade) existente de que uma pesquisa feita em outra língua possa circular nesse circuito acadêmico. No Brasil, a situação parece ser similar, Rosa e Alves (2011) analisaram os periódicos classificados no sistema Qualis da CAPES e concluíram que, entre os periódicos mais valorizados, 97\% deles são editados em língua inglesa e apenas 3\% em outras línguas.

\section{Os programas de doutorado e as pesquisas em marketing}

Outra explicação ao predomínio empírico-positivista pode derivar da falta de treinamento adequado, especialmente dos programas de doutorado, para realizar pesquisas conceituais, qualitativas ou abordagens de caráter interpretativo com qualidade (Cerchiaro, Sauerbronn, \& Ayrosa, 2004; Macinnis, 2011; Reibstein et al., 2009; Yadav, 2010). De acordo com Lehmann, McAlister e Staelin (2011), a pressão por publicações e o atual processo de revisão dos top journals, anteriormente discutido, afetaram os programas de doutorado, que trocaram a ênfase de treinamento em conhecimento em questões substanciais de marketing para tornarem-se mais especializados em disciplinas específicas e em abordagens metodológicas. Talvez, fosse importante incutir nos estudantes dos programas de doutorado uma abordagem mais intelectualmente guiada e menos metodologicamente dirigida para abordar os fenômenos de marketing, levando-os a entender que todas as abordagens metodológicas possuem limitações e que nenhuma é melhor do que outra (Brown et al., 2005; Macinnis, 2011).

Ademais, a disponibilidade de base de dados e as ferramentas estatísticas também têm trazido uma mudança importante no conteúdo e na estrutura dos programas de doutorado, não sendo incomum um oferecimento de treinamento rigoroso em metodologia de pesquisa e estatística em relação ao número menor de disciplinas conceituais de, por exemplo, epistemologia e história da ciência e do marketing (Reibstein et al., 2009; Yadav, 2010). De acordo com os autores, esforços deveriam ser empreendidos para restaurar o equilíbrio perdido entre os domínios conceituais e substantivos com os domínios metodológicos. 


\section{As lacunas no atendimento aos critérios de qualidade e o declínio de investigações conceituais}

Interessante ressaltar que os resultados do presente estudo, principalmente, quanto aos problemas identificados na discussão sobre as validades externas e nomológicas (vide Tabela 1 e Figura 6), novamente, acompanham, apesar das modificações já apontadas, aqueles encontrados anteriormente por Froemming et al. (2000a), indicando que, apesar do predomínio positivista nas últimas duas décadas, ainda, existem lacunas ao atendimento efetivo dos critérios de qualidade de uma pesquisa empírico-positivista.

Talvez, como decorrência das razões do predomínio positivista anteriormente discutidas, Firat $e t$ al. (2010) afirmam que a área de marketing parece demasiadamente preocupada com a reprodução e teste de modelos desenvolvidos por vezes em realidades distintas, e não com o desenvolvimento de teorias. Os pesquisadores em marketing adquiriram novas habilidades metodológicas e as investigações empíricas ficaram mais sofisticadas (Lehmann et al., 2011), por conseguinte, trazendo um foco metodológico que fragmentou a disciplina de Marketing, dessa maneira, diminuindo a quantidade de investigações conceituais integrativas (Yadav, 2010). Nesse sentido, Firat et al. (2010) constatam que, em poucas décadas, os artigos publicados em top journals, como o Journal of Marketing, modificaram-se, passando de poucas páginas com foco conceitual para apresentações com muitas fórmulas matemáticas e extensiva revisão de literatura, substanciais dados empíricos (muitas vezes, obtidos de estudantes) e duvidosas técnicas estatísticas e matemáticas. Brown et al. (2005) complementa afirmando que a disciplina de Marketing dá muita importância para a precisão dos argumentos e para a metodologia empregada, mas, frequentemente, essa postura leva simplesmente ao incrementalismo, e que artigos conceituais que tragam contribuição à área são críticos à vitalidade da disciplina (para uma discussão sobre desenvolvimento de uma estrutura de conceitualização em marketing e tipologia de tipos de contribuições conceituais ver Macinnis, 2011).

De acordo com o estudo de Yadav (2010), a mais profunda modificação proporcional de declínio dos artigos conceituais de desenvolvimento de teoria nos top journals ocorreu no Journal of Marketing, um periódico com um longo legado de publicações conceituais que ajudaram a construir a disciplina de Marketing. Apesar de o princípio do declínio dos artigos conceituais ter aparecido já no início da década de 90, foi, nos anos 2000, que ficou mais acentuado, mesmo com a preocupação da academia em relação à marginalização potencial da disciplina de Marketing e dos diversos chamamentos dos editoriais dos periódicos sobre a importância de tais artigos (Macinnis, 2011; Webster, 2005). O mesmo comportamento foi observado no presente estudo na realidade brasileira, notando-se uma queda expressiva da participação percentual de artigos conceituais da década de 90 $(36,9 \%)$ para os anos $2000(14,2 \%)$.

O crescimento dos estudos qualitativos poderia representar uma alternativa para a situação supracitada (Yadav, 2010). Firat et al. (2010) assentam posição contrária à dominação do paradigma positivista dominante e ao status atribuído de ciência superior, reivindicando espaço para outras metodologias (entre elas, a qualitativa) e que não sejam classificadas como de segunda linha. Conforme pontuam Firat et al. (2010), a noção de qualidade de ciência não deveria estar associada a uma ou outra perspectiva de pesquisa. Aparentemente, esta também parece ser uma manifestação da realidade brasileira, notadamente pelo leve incremento da participação percentual de estudos qualitativos dentro da produção de orientação positivista (vide Tabela 1 e Figura 1b) e também pelo fortalecimento da produção dentro de correntes não positivistas (vide Figura 1a).

\section{Os primeiros passos na direção de abordagens metodológicas alternativas}

Em especial, nas ciências sociais, seria importante também acolher métodos de investigação distintos daqueles tradicionais oriundos das ciências naturais, capazes de examinar certos significados emanados do mundo social, que poderiam ser capturados com a utilização de um método qualitativo de pesquisa com orientação interpretativista (Harrison \& Reilly, 2011; Hunt, 2010; Pinto \& Santos, 2008; Sauerbronn \& Ayrosa, 2010). Nesse sentido, Sauerbronn e Ayrosa (2010) pontuam que a 
proposta interpretativista de pesquisa ajudaria na compreensão do fenômeno organizacional, resultando em teorias mais ajustadas à realidade brasileira.

Em decorrência, a partir da década de 80, afirmam Pinto e Santos (2008), já se pode perceber, internacionalmente, um panorama de maior preocupação em propor abordagens alternativas para a compreensão dos fenômenos de consumo assentadas em uma perspectiva interpretativista. Assim, de acordo com Souza e Mello (2009), a disciplina de Marketing vem desferindo espaço para pressupostos teóricos e metodológicos de outras áreas do conhecimento, como, por exemplo, a antropologia.

Apesar de a adoção de uma postura interpretativista em marketing ser um fenômeno recente, o movimento tem conquistado fóruns de publicações e de discussões importantes, inclusive no Brasil (Rocha \& Rocha, 2007). Fortemente influenciada, particularmente pelos estudos em comportamento do consumidor, na década de 80, que trouxeram novas abordagens de pesquisa (ver, por exemplo, Belk, 1988; Levy, 1981; McCracken, 1986; Rook, 1985), a área de marketing incorporou novas opções às metodologias de natureza positivista. Partindo do pressuposto anteriormente apontado de que a produção nacional é fortemente influenciada pela produção norte-americana, seria bastante plausível esperar os reflexos na produção nacional dessa trilha mais interpretativista, o que de fato ocorreu - ver o estudo de Rocha e Rocha (2007) no tocante a uma retrospectiva desses estudos no Brasil. Apesar de recente, já é possível identificar estudos brasileiros que discutem (ver, por exemplo, Pinto \& Santos, 2008; Rocha \& Rocha, 2007; Sauerbronn \& Ayrosa, 2010) e aplicam (ver, por exemplo, Barboza \& Ayrosa, 2010; Costa \& Leão, 2010; Netto, Kruger, Brei, Perin, \& Sampaio, 2010; Oliveira \& Vieira, 2010; Schweig \& Silveira, 2010) os pressupostos interpretativistas de pesquisa. Os dados analisados neste estudo mostram um crescimento de artigos que relatam estudos empíricos com base em uma abordagem interpretativista, registrando já um percentual expressivo de $13 \%$ dos trabalhos em 2010 (vide Figura 1a).

Brown et al. (2005) acreditam que, para novos caminhos, a disciplina de Marketing precisaria ainda ter uma abordagem mais mente aberta, aprendendo mais sobre como os problemas são abordados pelas diferentes perspectivas e valorizando a pesquisa pelo que é e contribui, ao invés do quanto ela é similar à abordagem dominante a qual define o que é uma boa pesquisa, com isso, desvalorizando tudo que for diferente.

\section{Os benefícios e beneficiários da pesquisa em marketing}

Além da necessidade dessa postura mais democrática, a forma reducionista, estreitamente especificada e fragmentada da pesquisa, acaba por não se adequar aos problemas multifuncionais e interdisciplinares dos administradores (Reibstein et al., 2009). De acordo com os autores, poucos problemas empresariais podem ser resolvidos exclusivamente por uma área e uma perspectiva, sendo que ambas as abordagens comportamental e quantitativa são necessárias, assim, necessitando mecanismos que estimulem a cooperação entre elas. Nesse sentido, os autores acreditam que os acadêmicos não estão ouvindo as necessidades e os problemas que as empresas enfrentam, tornando, por conseguinte, a disciplina de Marketing menos relevante aos gestores (para uma discussão sobre a definição e elucidação de relevância empresarial ver Jaworski, 2011). Ao analisar modelos de decisão em marketing, Lilien (2011) constatou a baixa aplicabilidade e adoção desses modelos pelas empresas, sugerindo uma necessidade de mudanças aos acadêmicos e gestores para trabalharem mais estreitamente relacionados. Lutz (2011) também reclama a necessidade de mais colaboração entre a academia e as organizações no sentido de assegurar uma produção e disseminação de conhecimento relevante.

Na mesma linha, Mascarenhas, Zambaldi e Moraes (2011) alegam uma tensão envolvendo o rigor científico da produção nacional e a relevância dessa produção, voltada essencialmente à academia, que reserva pouca preocupação com a aplicabilidade dos estudos à problemática enfrentada por administradores no âmbito organizacional (Bertero, Caldas, \& Wood, 2005). Os resultados do presente estudo corroboram tal alegação à medida que anotaram, da década de 90 para os anos 2000 , uma queda significativa (de $72,3 \%$ para $58,3 \%$ ) no que se refere à exposição de recomendações 
aplicadas nos artigos analisados, enquanto que as recomendações a novas pesquisas acadêmicas tiveram o sentido inverso (aumento de 40,2\% para 68,1\%) - vide Tabela 1 e Figura 6.

Em síntese, numa comparação entre a década de 90 e os anos 2000, pode-se destacar algumas saliências. Percebe-se claramente o fortalecimento dos estudos de natureza causal, a manutenção da hegemonia descritiva e a queda da aplicação da natureza exploratória. É de se registrar, ainda, um aparente foco mais acadêmico nas publicações durante os anos 2000, bem como uma preocupação de teste de teorias de base, supostamente envolvendo relações entre construtos conforme se verifica maior índice de trabalhos de natureza causal, maior número de artigos com teorias de base aprofundadas e explicitação de modelos de pesquisa, maior constância de descrição da operacionalização de variáveis e, também, mais intensidade na preocupação com as validades externa e nomológica, maior amplitude de estudos que registram recomendação para pesquisas futuras e limites do estudo e menor percentual de recomendações aplicadas.

\section{Considerações Finais}

O foco central deste artigo esteve na avaliação da evolução das características metodológicas básicas da produção científica da área de marketing, no Brasil, nos anos 2000, comparando os resultados com aqueles apresentados na década de 90, dessa forma, visando a avaliar tendências da área, estado atual das pesquisas, bem como traçar perspectivas futuras para a área em análise. Para tanto, foi realizado um levantamento dos artigos de marketing nos últimos 11 anos (2000 a 2010) nos principais periódicos de administração do Brasil (RAC, RAC-Eletrônica, RAE, RAE Eletrônica, BAR, RAUSP, RAM), assim como nos anais dos mais importantes encontros de pós-graduação no país que possuem a divisão de marketing (EnANPAD e EMA). A principal conclusão foi a de que a análise dos artigos de base empírica publicados, em termos gerais, sinaliza uma busca pelo aprofundamento dos conhecimentos e da base conceitual da área de marketing no Brasil.

É de se registrar a curiosa constância na desatenção com a discussão sobre as validades externa e nomológica dos estudos realizados, apesar de um expressivo incremento percentual ao longo dos anos 2000. Em sentido contrário, destaca-se o positivo avanço do apontamento dos limites dos estudos e do desenvolvimento de maiores recomendações para futuras pesquisas acadêmicas.

Por fim, os resultados parecem indicar maior diversidade de abordagens de pesquisa e maior cuidado com a qualidade dos estudos de marketing produzidos no Brasil, nos anos 2000, quando comparados com a década de 90 . Parece que o movimento de pesquisadores em avaliar a qualidade da produção científica de marketing, no final da década de 90 e início dos anos 2000 , trouxe à tona a necessidade de um aprimoramento da qualidade dos estudos na área, assim, refletindo, nos anos 2000, em pesquisas mais criteriosas quanto aos critérios de qualidade dos artigos.

Cabe ressaltar que, conquanto o rigor aplicado na realização da presente pesquisa, deve-se relacionar como limites deste estudo os seguintes pontos: (a) as conclusões do estudo estão restritas às publicações dos periódicos de administração do Brasil (RAC, RAC-Eletrônica, RAE, RAE Eletrônica, BAR, RAUSP, RAM), assim como dos anais dos encontros de pós-graduação no país que possuem a divisão de marketing (EnANPAD e EMA) e ao período considerado; e (b) a subjetividade implícita de cada avaliador em suas análises individuais pode ter representado conclusões distintas para uma mesma situação, apesar dos critérios claros de análise e das reuniões de revisão de dúvidas, além da verificação dos juízes ter encontrado um adequado nível de concordância.

A partir dos resultados deste estudo, sugerem-se, como pesquisas futuras, a comparação dos resultados da área de marketing com outras áreas, bem como dos resultados nacionais com os de outros países, além da avaliação específica e detalhada por tipo de método (survey, qualitativa, experimental e fenomenológica). 


\section{Nota}

${ }^{1}$ Note-se que os dados relativos à produção de base empírica não positivista da década de 90 não foram registrados no
gráfico dada a sua irrelevância no período em questão (Rocha \& Rocha, 2007) .

\section{Referências}

Andrade, J., \& Mazzon, J. A. (2010, maio). O discurso publicitário e o poder do receptor: um estudo sobre a evolução dos anúncios impressos no mercado brasileiro entre 1968-2008. Anais do Encontro de Marketing da ANPAD, Florianópolis, SC, Brasil, 4.

Barboza, R. A., \& Ayrosa, E. A. T. (2010, maio). Um estudo empírico sobre a construção da identidade social do consumidor de Toy Art. Anais do Encontro de Marketing da ANPAD, Florianópolis, SC, Brasil, 4.

Belk, R. W. (1988). Possessions and the extended self. Journal of Consumer Research, 15(2), 139168.

Bertero, C. O., Caldas, M. P., \& Wood, T., Jr. (2005). Produção científica em administração no país. São Paulo: Atlas.

Bolton, R. N. (2011). To JM on its 75th anniversary. Journal of Marketing, 75(4), 129-131. doi: 10.1509/jmkg.75.4.129

Brown, S. W., Webster, F. E., Jr., Steenkamp, J.-B. E. M., Wilkie, W. L., Sheth, J. N., Sisodia, R. S., Kerin, R. A., MacInnis, D. J., McAlister, L., Raju, J. S., Bauerly, R. J., Johnson, D. T., Singh, M., \& Staelin, R. (2005). Marketing renaissance: opportunities and imperatives for improving marketing thought, practice, and infrastructure. Journal of Marketing, 69(4), 1-25. doi: 10.1509/jmkg.2005.69.4.1.

Caldas, M. P., Tinoco, T., \& Chu, R. A. (2003, setembro). Análise bibliométrica dos artigos de RH publicados no EnANPAD, na Década de 1990: um mapeamento a partir das citações dos heróis, endogenias e jactâncias que fizeram a história recente da produção científica da área. Anais do Encontro Nacional da Associação Nacional de Pós-Graduação e Pesquisa em Administração, Atibaia, SP, Brasil, 27.

Cardoso, R. L., Pereira, C. A., \& Guerreiro, R. (2004, setembro). A produção acadêmica em custos no âmbito do EnANPAD: uma análise de 1998 a 2003. Anais do Encontro Nacional da Associação Nacional de Pós-Graduação e Pesquisa em Administração, Curitiba, PR, Brasil, 28.

Casotti, L. (1998, setembro). Marketing moderno e consumidor pós-moderno. Anais do Encontro Nacional da Associação Nacional de Pós-Graduação e Pesquisa em Administração, Foz do Iguaçu, PR, Brasil, 22.

Casotti, L. (1999, setembro). O que é a pesquisa do consumidor? Reflexões geradas a partir de um problema prático. Anais do Encontro Nacional da Associação Nacional de Pós-Graduação e Pesquisa em Administração, Foz do Iguaçu, PR, Brasil, 23.

Cerchiaro, I., Sauerbronn, J., \& Ayrosa, E. (2004, novembro). Uma visão alternativa da pesquisa em marketing: como a fenomenologia pode contribuir para gerar conhecimento de marketing. Anais do Encontro de Marketing da ANPAD, Porto Alegre, RS, Brasil, 1.

Churchill, G. A., Jr. (1999). Marketing research: methodological foundation. Orlando: The Dryden Press. 
Costa, F. Z. N., \& Leão, A. L. M. S. (2010, maio). Formações discursivas de uma marca global num contexto local: um estudo foto-etnográfico da presença imagética da Coca-Cola numa grande região metropolitana brasileira, inspirado no método arqueológico de Michel Foucault. Anais do Encontro de Marketing da ANPAD, Florianópolis, SC, Brasil, 4.

Durante, D. G., \& Maurer, S. A. S. (2007, setembro). Gestão do conhecimento e da informação: revisão da produção científica do período 2000-2005. Anais do Encontro Nacional da Associação Nacional de Pós-Graduação e Pesquisa em Administração, Rio de Janeiro, RJ, Brasil, 31.

Ellison, G. (2002). Evolving standards for academic publishing: a q-r theory. Journal of Political Economy, 110(5), 994-1034. doi: 10.1086/341871

Faria, A. (2004, setembro). Em busca de relevância no âmbito de estratégia de marketing. Anais do Encontro Nacional da Associação Nacional de Pós-Graduação e Pesquisa em Administração, Curitiba, PR, Brasil, 28.

Farias, S. A. (2004, novembro). Em busca da inovação no marketing brasileiro: discutindo o processo de publicação de artigos em revistas e congressos. Anais do Encontro de Marketing da ANPAD, Porto Alegre, RS, Brasil, 1.

Firat, A. F., Gummesson, E., Levy, S. J., Tadajewski, M., Brodie, R. J., Hackley, C., Lee, N., Baker, M. J., Pels, J., Alpert, F., \& Varey, R. J. (2010). Commentaries on the state of journals in marketing. Marketing Theory, 10(4), 437-455.

Froemming, L. M. S, Luce, F. B., Perin, M. G., Sampaio, C. H., Beber, S. J. N., \& Trez, G. (2000b). Análise da qualidade dos artigos científicos da área de marketing no Brasil: as pesquisas survey na década de 90. Revista de Administração Contemporânea, 4(3), 201-219. doi: 10.1590/S141565552000000300011

Froemming, L. M. S, Luce, F. B., Perin, M. G., Sampaio, C. H., Beber, S. J. N., \& Trez, G. (2000a). Inventário de artigos científicos na área de marketing no Brasil. Revista de Administração Contemporânea, 4(2), 159-173. doi: 10.1590/S1415-65552000000200009

Gonçalves, N. G., Gonçalves, S. A., \& Augusto, P. O. M. (2004, setembro). Sobre a relação estado e educação na produção acadêmica brasileira (1971-2000): temas, críticas e expectativas. Anais do Encontro Nacional da Associação Nacional de Pós-Graduação e Pesquisa em Administração, Curitiba, PR, Brasil, 28.

Hamel, R. (2007). The dominance of English in the international scientific periodical literature and the future of language use in science. AILA Review, 20(1), 53-71. doi: 10.1075/aila.20.06ham

Harrison, R. L., \& Reilly, T. M. (2011). Mixed methods designs in marketing research. Qualitative Market Research: an International Journal, 14(1), 7-26. doi: 10.1108/13522751111099300

Hoppen, N., Lapointe, L., \& Moreau, E. (1997, setembro). Avaliação de artigos de pesquisa em sistemas de informação: proposta de um guia. Anais do Encontro Nacional da Associação Nacional de Pós-Graduação e Pesquisa em Administração, Rio das Pedras, RJ, Brasil, 21.

Huertas, M. K. Z., \& Urdan, A. T. (2004, setembro). Propaganda de medicamentos no Brasil: informação ou emoção? Anais do Encontro Nacional da Associação Nacional de PósGraduação e Pesquisa em Administração, Curitiba, PR, Brasil, 28.

Hunt, M. R. (2010). Active waiting: habits and the practice of conducting qualitative research. International Journal of Qualitative Methods, 9(1), 69-76. 
lizuka, E. S., \& Sano, H. (2004, setembro). O terceiro setor e a produção acadêmica. Anais do Encontro Nacional da Associação Nacional de Pós-Graduação e Pesquisa em Administração, Curitiba, PR, Brasil, 28.

Jaime, P., Jr. (2000, setembro). Breves notas sobre etnomarketing, ou das relações entre a antropologia do consumo e a administração mercadológica. Anais do Encontro Nacional da Associação Nacional de Pós-Graduação e Pesquisa em Administração, Florianópolis, SC, Brasil, 24.

Jaworski, B. J. (2011). On managerial relevance. Journal of Marketing, 75(4), 211-224. doi: 10.1509/jmkg.75.4.211

Kohli, A. K. (2011). Introduction to the Journal of Marketing 75th anniversary special section. Journal of Marketing, 75(4), 128. doi: 10.1509/jmkg.75.4.128

Kovacs, M. H., Leão, A. L. M., Vieira, R. S. G., Barbosa, L., \& Dias, C. M. (2004, novembro). Podemos confiar nos resultados de nossas pesquisas? Uma avaliação dos procedimentos metodológicos nos artigos de marketing do EnANPAD. Anais do Encontro de Marketing da $A N P A D$, Porto Alegre, RS, Brasil, 1.

Lehmann, D. R., McAlister, L., \& Staelin, R. (2011). Sophistication in research in marketing. Journal of Marketing, 75(4), 155-165. doi: 10.1509/jmkg.75.4.155

Levy, S. (1981). Interpreting consumer mythology: a structural approach to consumer behavior. Journal of Marketing, 45(3), 49-61.

Lilien, G. L. (2011). Bridging the academic-practitioner divide in marketing decision models. Journal of Marketing, 75(4), 196-210. doi: 10.1509/jmkg.75.4.196

Lutz, R. J. (2011). Marketing scholarship 2.0. Journal of Marketing, 75(4), 225-234. doi: 10.1509/jmkg.75.4.225

Macinnis, D. J. (2011). A framework for conceptual contributions in marketing. Journal of Marketing, 75(4), 136-154. doi: 10.1509/jmkg.75.4.136

Mascarenhas, A. O., Zambaldi, F., \& Moraes, E. A. (2011). Rigor, relevância e desafios da academia em administração: tensões entre pesquisa e formação profissional. Revista de Administração de Empresas, 51(3), 265-279. doi: 10.1590/S0034-75902011000300007

McCracken, G. (1986). Culture and consumption: a theoretical account of the structure and movement of the cultural meaning of consumer goods. Journal of Consumer Research, 13(1), 71-84.

Melo, P. L. R., \& Andreassi, T. (2010). Publicação científica nacional e internacional sobre franchising: levantamento e análise do período 1998-2007. Revista de Administração Contemporânea, $\quad 14(2), \quad 268-288 . \quad$ Recuperado de http://www.scielo.br/pdf/rac/v14n2/v14n2a06.pdf. doi: 10.1590/S1415-65552010000200006

Mendonça, M. B. (2011, maio). Técnicas de prospecção e análise de cenários futuros nos governos e administração pública do Brasil: revisão da produção científica brasileira de 2001 a 2010. Anais do Encontro de Estudos em Estratégia, Porto Alegre, RS, Brasil, 5.

Meriläinen, S., Tienari, J., Thomas, R., \& Davies, A. (2008). Hegemonic academic practices: experiences of publishing from periphery. Organization, 15(4), 584-597. doi: $10.1177 / 1350508408091008$

Nascimento, A. R., Junqueira, E., \& Martins, G. A. (2010). Pesquisa acadêmica em contabilidade gerencial no Brasil: análise e reflexões sobre teorias, metodologias e paradigmas. Revista de Administração Contemporânea, 14(6), 1113-1133. Recuperado de http://www.scielo.br/pdf/rac/v14n6/v14n6a08.pdf. doi: 10.1590/S1415-65552010000700008 
Nassif, V. M. J., Silva, N. B., Ono, A. T., Bontempo, P. C., \& Tinoco, T. (2009, setembro). Empreendedorismo: área em evolução? Uma revisão dos estudos e artigos publicados entre 2001 e 2008. Anais do Encontro Nacional da Associação Nacional de Pós-Graduação e Pesquisa em Administração, São Paulo, SP, Brasil, 33.

Netto, C. F., Kruger, P. L., Brei, V. A., Perin, M. G., \& Sampaio, C. H. (2010, setembro). Significado cultural dos bens de consumo em um concurso de beleza infantil. Anais do Encontro Nacional da Associação Nacional de Pós-Graduação e Pesquisa em Administração, Rio de Janeiro, RJ, Brasil, 34.

Oliveira, J. S., \& Vieira, F. G. D. (2010, maio). Com os pés na igreja e as mãos nas compras: compreendendo a influência religiosa na constituição dos significados atribuídos ao consumo de presentes de natal por jovens cristãos. Anais do Encontro de Marketing da ANPAD, Florianópolis, SC, Brasil, 4.

Perin, M. G., Sampaio, C. H., Froemming, L. M. S., \& Luce, F. B. (2000, setembro). A pesquisa survey em artigos de marketing nos Enanpads da década de 90. Anais do Encontro Nacional da Associação Nacional de Pós-Graduação e Pesquisa em Administração, Florianópolis, SC, Brasil, 24.

Pinto, M. R. de, \& Lara, J. D. (2008). O que se publica sobre comportamento do consumidor no Brasil, afinal? Revista de Administração da UFSM, 1(3), 85-100.

Pinto, M. R. de, \& Santos, L. L. S. da (2008). Em busca de uma trilha interpretativista para a pesquisa do consumidor: uma proposta baseada na fenomenologia, na etnografia e na grounded theory. RAE-Eletrônica, 7(2). Recuperado de http://www.scielo.br/pdf/raeel/v7n2/09.pdf. doi: 10.1590/S1676-56482008000200009

Reibstein, D. J., Day, G., \& Wind, J. (2009). Guest editorial: is marketing academia losing its way? Journal of Marketing, 73(4), 1-3. doi: 10.1509/jmkg.73.4.1

Rocha, A., \& Rocha, E. (2007). Paradigma interpretativo nos estudos de consumo: retrospectiva, reflexões e uma agenda de pesquisas para o Brasil. Revista de Administração de Empresas, 47(1), 71-80.

Rodrigues, S., \& Carrieri, A. (2001). A tradição anglosaxônica em estudos organizacionais brasileiros. Revista de Administração Contemporânea, 5(Ed. Especial), 81-102. doi: 10.1590/S141565552001000500005

Rook, D. W. (1985). The ritual dimension of consumer behavior. Journal of Consumer Research, 12(3), 251-264.

Rosa, A. R., \& Alves, M. A. (2011). Pode o conhecimento em gestão e organização falar português? Revista de Administração de Empresas, 51(3), 255-264. doi: 10.1590/S003475902011000300006

Rossi, C. A. V., \& Silveira, T. (1999, setembro). Pesquisa sobre culturas nacionais: o inexorável futuro do marketing na globalização. Anais do Encontro Nacional da Associação Nacional de PósGraduação e Pesquisa em Administração, Foz do Iguaçu, PR, Brasil, 23.

Sampaio, C. H., \& Perin, M. G. (2006). Pesquisa científica da área de marketing: uma revisão histórica. Revista de Administração Contemporânea, 10(2), 179-202. doi: 10.1590/S141565552006000200010

Sauerbronn, J. F. R., \& Ayrosa, E. A. T. (2010). Sobre convergência e a prática metodológica do interacionismo interpretativo na pesquisa acadêmica de marketing. Revista de Administração Contemporânea, 14(5), 854-870. Recuperado de http://www.scielo.br/pdf/rac/v14n5/v14n5a06.pdf. doi: 10.1590/S1415-65552010000500006 
Schweig, C., \& Silveira, T. (2010, setembro). A afinidade com um país estrangeiro e seus reflexos na construção de significados de consumo de alimentos: Mangia che te fa bene. Anais do Encontro Nacional da Associação Nacional de Pós-Graduação e Pesquisa em Administração, Rio de Janeiro, RJ, Brasil, 34.

Souza, A. F., Neto, \& Mello, S. C. B. (2009). Olhando além do "primeiro estruturalismo" para a pesquisa em marketing. Revista de Administração Contemporânea, 13(4), 525-544. Recuperado de http://www.scielo.br/pdf/rac/v13n4/a02v13n4.pdf. doi: 10.1590/S1415-65552009000400002

Tonelli, M. J., Caldas, M. P., Lacombe, B. M. B., \& Tinoco, T. (2004, setembro). O mapa da partilha: análise das áreas de comportamento organizacional e gestão de pessoas antes e depois da cisão da área de "recursos humanos" no Enanpad, 1991-2003. Anais do Encontro Nacional da Associação Nacional de Pós-Graduação e Pesquisa em Administração, Curitiba, PR, Brasil, 28.

Vieira, F. G. D. (1998, setembro). Por quem os sinos dobram? Uma análise da publicação científica na área de Marketing do ENANPAD. Anais do Encontro Nacional da Associação Nacional de Pós-Graduação e Pesquisa em Administração, Foz do Iguaçu, PR, Brasil, 22.

Vieira, F. G. D. (1999, setembro). Ações empresariais e prioridades de pesquisa em marketing: tendências no Brasil e no mundo segundo a percepção dos acadêmicos brasileiros. Anais do Encontro Nacional da Associação Nacional de Pós-Graduação e Pesquisa em Administração, Foz do Iguaçu, PR, Brasil, 23.

Vieira, F. G. D. (2000, setembro). Panorama acadêmico-científico e temáticas de estudos de marketing no Brasil. Anais do Encontro Nacional da Associação Nacional de Pós-Graduação e Pesquisa em Administração, Florianópolis, SC, Brasil, 24.

Vieira, R., Dias, C., Rodrigues, J., Filho, \& Anjos, M., Neto (2002, setembro). O conhecimento do marketing sob os olhos da teoria crítica. Anais do Encontro Nacional da Associação Nacional de Pós-Graduação e Pesquisa em Administração, Salvador, BA, Brasil, 26.

Webster, F. E., Jr. (2005). A perspective on the evolution of marketing management. Journal of Public Policy \& Marketing, 24(1), 121-126.

Yadav, M. S. (2010). The decline of conceptual articles and implications for knowledge development. Journal of Marketing, 74(1), 1-19. doi: 10.1509/jmkg.74.1.1 